\title{
Coronary atherosclerosis within a myocardial bridge, not a benign condition
}

\author{
Robbert J de Winter, Wouter E M Kok, Jan J Piek
}

\begin{abstract}
In patients with myocardial bridging, the area within the bridge usually remains free from atherosclerotic disease. The case of a 47 year old man is described who had the rare combination of myocardial bridging with an atherosclerotic plaque within the area of bridging, which was detected with intravascular ultrasound but not with coronary angiography. The clinical history of the patient demonstrates that this is not a benign condition. In symptomatic patients the bridged segment should be screened for the presence of plaque with intracoronary ultrasound.

(Heart 1998;80:91-93)
\end{abstract}

Keywords: myocardial bridging; intravascular ultrasound; atherosclerotic plaque

Myocardial bridging is defined as a segment of a major epicardial coronary artery running intramurally through the myocardium. Although a common finding in necropsy studies $(15-85 \%),{ }^{12}$ it is less frequently detected as a systolic narrowing of the artery at angiography $(0.51-2.5 \%))^{3}{ }^{4}$ The milking effect of myocardial bridging can be accentuated by the use of intracoronary nitroglycerin, which will increase the incidence of myocardial bridging detected on the angiogram. ${ }^{4}$ Myocardial bridging has been considered a benign condition, ${ }^{56}$ although it has been associated with myocardial ischaemia, ${ }^{3-9}$ tachycardia induced ischaemia, ${ }^{10}$ conduction disturbances, ${ }^{11}$ myocardial infarction, ${ }^{12-14}$ and sudden death. ${ }^{14}{ }^{15}$ Both pathological and ultrasound studies suggest that atherosclerotic lesions are uncommon within the bridging segment, but are common proximal to the bridge. ${ }^{16-18}$

We describe a patient with an atherosclerotic lesion within an area of severe myocardial bridging of the left anterior descending coronary artery (LAD) who experienced one episode of acute transmural anterior ischaemia and who suffered two anterior myocardial infarctions. Intravascular ultrasound revealed an atherosclerotic lesion within the bridge that was not apparent on the angiogram.

\section{Case report}

A 47 year old man was admitted to the emergency room with typical chest pain that had started 10 minutes earlier. The ECG showed $10 \mathrm{~mm}$ ST segment elevation in leads V1 to V6, I, and aVL. After $0.5 \mathrm{mg}$ nitroglycerin and $10 \mathrm{mg}$ nifedipine the chest pain subsided and the ECG normalised. This episode did not result in raised creatine kinase MB. The patient's medical history revealed no previous chest pain and there were no exertional anginal complaints. He smoked about 20 cigarettes daily, total serum cholesterol was $4 \mathrm{mmol} / 1$. A diagnostic coronary angiogram, performed when the patient was stable, showed normal coronary arteries but with myocardial bridging with complete systolic disappearance of a $1.5 \mathrm{~cm}$ long segment in the mid-portion of the LAD (fig $1 \mathrm{~A}$ and $\mathrm{B}$ ).

The episode of chest pain was considered to be caused by coronary spasm, possibly in combination with myocardial bridging, and he was treated with aspirin $100 \mathrm{mg}$ and nifedipine $60 \mathrm{mg}$ daily. A treadmill exercise test was negative and the patient was discharged. Four weeks later, he was admitted with sudden onset of chest pain; again the ECG showed marked ST segment elevations in anterolateral leads without improvement after the administration of nitroglycerin and nifedipine. An urgent diagnostic angiogram revealed an occlusion of the LAD in the middle of the bridging segment (fig 1C). Angioplasty was performed and flow was restored after crossing of the guidewire. A residual stenosis was dilated with a $3.0 \mathrm{~mm}$ balloon, and angiography after PTCA showed an excellent result.

At the end of the angioplasty, intracoronary ultrasound was performed, after intracoronary nitroglycerin, with a $2.9 \mathrm{~F}$ mechanical single element $30 \mathrm{MHz}$ system (Cardiovascular Imaging Systems Inc, Sunnyvale, California, USA). The ultrasound transducer was positioned in the left anterior descending artery distal to the myocardial bridge (recognised by its location between two septal branches), and was slowly pulled back manually. An atherosclerotic plaque was observed distal as well as proximal to the bridge (fig $2 \mathrm{~A}$ and $\mathrm{D}$ ). Lumen area measured during end diastole at the proximal site (fig $2 \mathrm{~A}$ ) was $7.4 \mathrm{~mm}^{2}$ and plaque area was $1.7 \mathrm{~mm}$. At the distal site (fig 2D) lumen area was $4.4 \mathrm{~mm}$ and plaque area

Meibergdreef 9, 1105 AZ

Amsterdam, Netherl

Accepted for publication 13 August 1997 

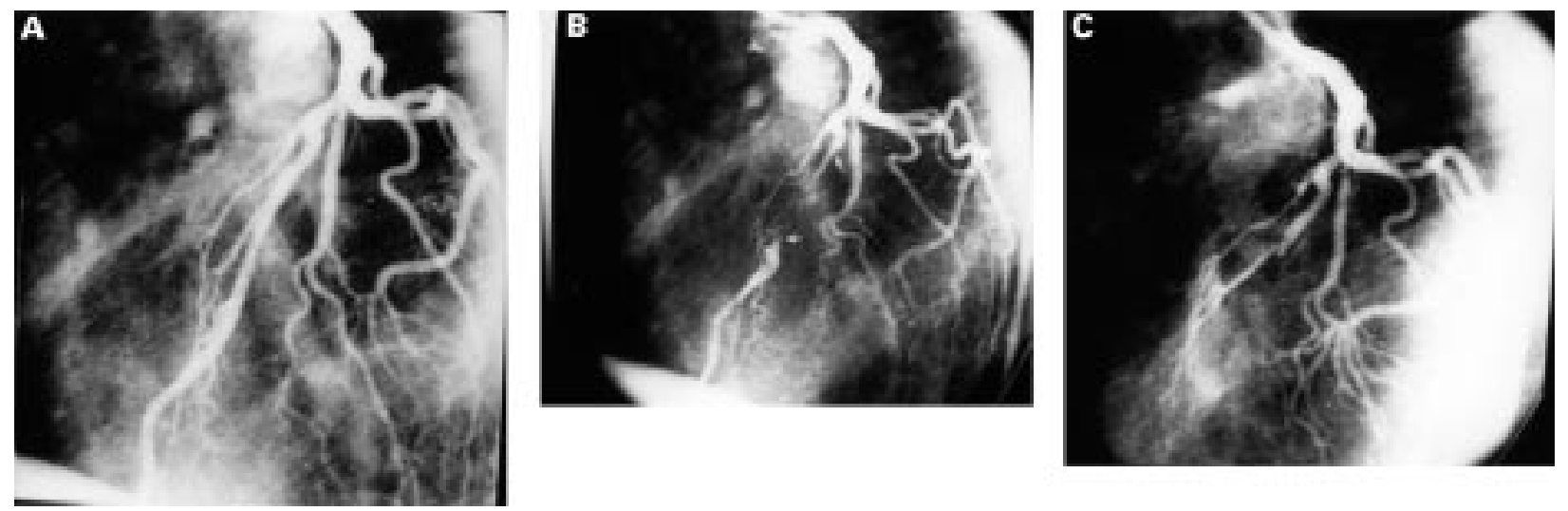

Figure 1 Coronary angiogram of the left coronary artery in caudo-cranial projection performed during the first admission. Diastolic $(A)$ and systolic (B) frames demonstrating complete obliteration of the approximately $15 \mathrm{~mm}$ long intramural portion of the left anterior descending artery. Arrows indicate the proximal and distal parts of the bridged segment. (C) Occlusion of the left anterior descending artery four weeks later when the patient was readmitted with an acute anterior infarction. The site of the occlusion is in the middle section of the bridge.

$0.9 \mathrm{~mm}$. At the middle portion of the bridge (fig 2C), the imaging catheter was caught within the artery during systolic narrowing. Within the bridge, a ruptured, soft atheroscle-

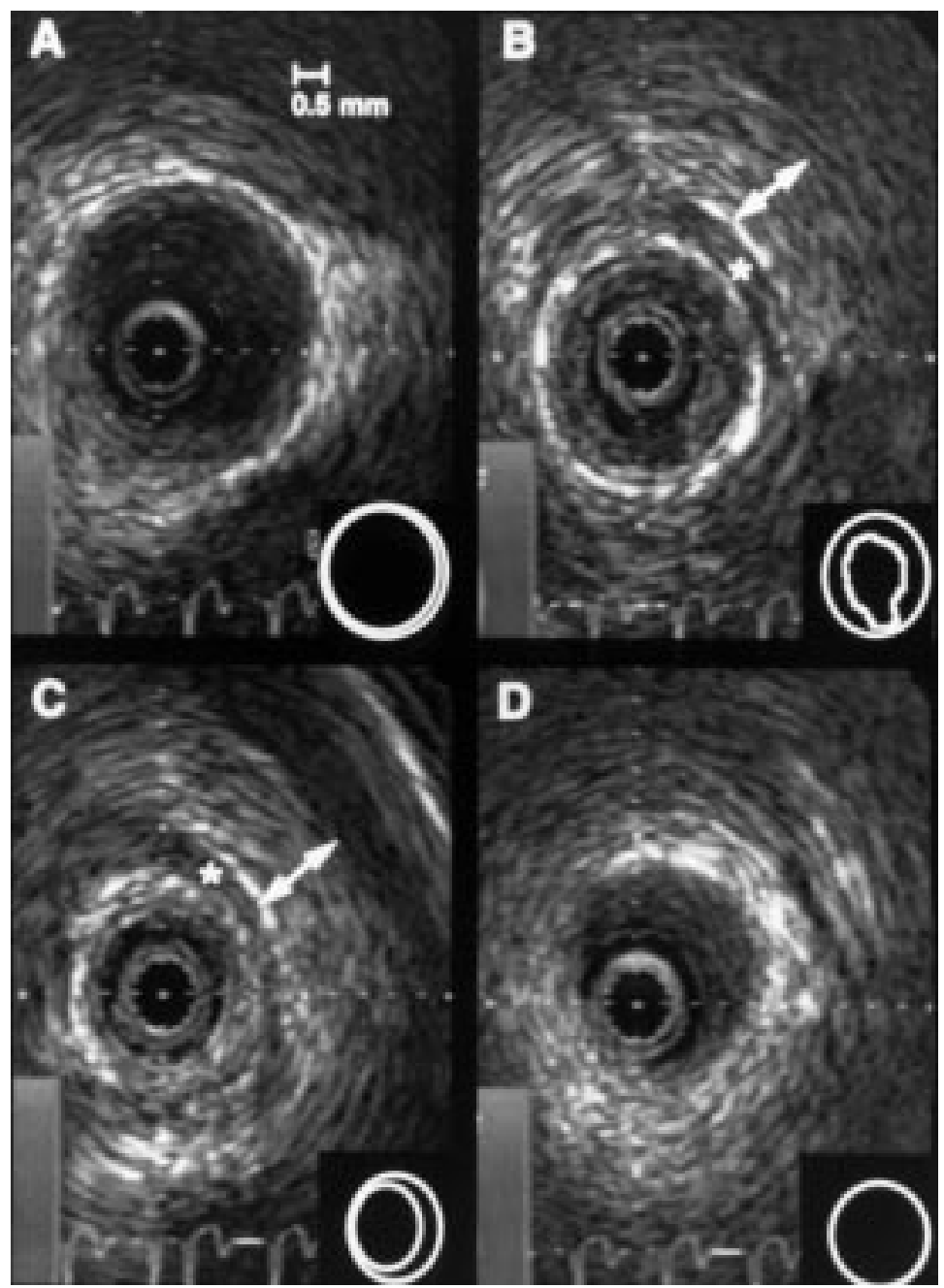

Figure 2 Intracoronary ultrasound images of the patient after PTCA of the left anterior descending artery within the myocardial bridge. A to D represent the course of the left anterior descending artery from proximal to distal. $B$ and $C$ are located within the myocardial bridge. A soft atheromatous plaque was detected that was not apparent on the coronary angiogram. Plaque rupture (B) was probably the result of the PTCA procedure. Asterisks indicate an echolucent band surrounding the artery within the bridge that probably represents adipose tissue around the artery. Vessel lumen and media bounded area are indicated in the insets, and plaque rupture can be seen in panel B at 6 o'clock. rotic lesion was apparent (fig $2 \mathrm{~B}$ ). At this cross section, the lumen area measured at end diastole was $2.7 \mathrm{~mm}^{2}$ and plaque area was $3.3 \mathrm{~mm}$. Interestingly, an echolucent band with a maximum thickness of $0.5 \mathrm{~mm}$ was visible between the myocardial bridge and the vessel adventitia that ran along the full length of the area of myocardial bridging (asterisks, fig 2B and $\mathrm{C}$ ). This band probably represents adipose tissue around the bridged artery. The myocardial bridge width was estimated at $1.5 \mathrm{~mm}$. The patient was treated with aspirin $100 \mathrm{mg}$, nifedipine $60 \mathrm{mg}$, atenolol $100 \mathrm{mg}$, and simvastatin $10 \mathrm{mg}$.

Follow up was uneventful with repetitive negative exercise stress tests until three years later when the patient was admitted with acute chest pain and electrocardiographic signs of acute anterior infarction. A diagnostic angiogram again showed occlusion of the LAD at exactly the same site as three years previously, and primary PTCA was again performed successfully. IVUS examination of the LAD demonstrated no progression nor regression of the atherosclerotic lesion in the area of myocardial bridging, and no change in atherosclerotic disease proximal or distal to the bridge. This time, we treated the patient with grafting of the left mammary artery on the LAD with minimal invasive surgery, and the patient was symptom free four months after the operation.

\section{Discussion}

Observations from several pathological studies on series of hearts with bridged coronary arteries have shown that atherosclerotic lesions within the bridging coronary segment are rare, ${ }^{16}{ }^{17}$ although the so called protective effect of the intramural course of the artery has been questioned in one early report. ${ }^{2}$ The reason for atherosclerosis being confined mainly to the part of the vessel proximal to the bridge is unclear, but may be related to local wall stress, flow and shear stress conditions, and subsequent injury to the vessel wall. ${ }^{18}{ }^{19} \mathrm{Ge}$ et al reported a group of 14 patients with typical and atypical angina that showed systolic narrowing of a portion of the LAD. ${ }^{18}$ None of these patients had a history of myocardial infarction; $86 \%$ had atherosclerotic lesions, but these were 
all located proximal to the bridged segment with no atherosclerotic lesions within the bridged segment. Our patient had a soft atherosclerotic plaque within the area of bridging. This lesion was not visible on the coronary angiogram but was detected with IVUS. In a recent editorial, Virmani et al speculated that systolic narrowing of the coronary artery should be at least $75 \%$ to cause ischaemia where mild to moderate compression may not cause ischaemia. ${ }^{20}$ In our patient, however, the combination of severe systolic narrowing with soft plaque within the bridged segment did not result in exercise induced ischaemia, but rather in repeated acute occlusion of the vessel. Although intracoronary stenting of myocardial bridges in symptomatic patients has been described in a preliminary report, ${ }^{21}$ we feared mechanical trauma to the stent and so decided to perform mammary artery bypass grafting in this patient after the third episode of acute occlusion of the vessel that had twice resulted in acute myocardial infarction.

We conclude that myocardial bridging with a plaque within the bridged area may be associated with acute myocardial infarction, and should not be considered a benign condition in symptomatic patients. Atherosclerotic lesions proximal, or rarely, within the area of bridging may remain undetected by coronary angiography. This case report demonstrates that intracoronary ultrasound can detect such lesions and in symptomatic patients the bridged segment should be screened for the presence of plaque with intracoronary ultrasound. In symptomatic patients with myocardial bridging and an atherosclerotic lesion within the bridged segment, bypass grafting should be considered.

We thank K T Koch, R A M van Liebergen, R J G Peters, and A $\mathrm{C}$ vd Wal for their help, advice, and critical comments.

1 Polachek P. Relation of myocardial bridges and loops on the coronary arteries to coronary occlusions. Am Heart $\mathcal{F}$ 1961;61:44-52.

2 Edwards JC, Burnsides C, Swarm RL, Lansing AJ. Arteriosclerosis in the intramural and extramural portions of coronary arteries in human heart. Circulation 1956;13:23541.
3 Nobel J, Bourassa MG, Petitclerc R, Dyrda I. Myocardial bridging and milking effect of the left anterior descending coronary artery: normal variant or obstruction? Am f Cardiol 1976;37:993-9.

4 Ishimori T, Raizner AF, Chabine RA, Awdeh M, Luchi R. Myocardial bridges in man: clinical correlations and angiographic accentuation with nitroglycerin. Cathet Cardiovasc Diagn 1977;3:59-65.

5 Roberts WC. Adult congenital heart disease. Philadelphia: Davis, 1987.

6 Roberts WC, Dicicco BS, Waller BF, Kishel JC, McManus $\mathrm{BM}$, Dawson SL, et al. Origin of the left main from the right coronary artery or from the right coronary sinus with intramural tunneling to the left side of the heart via the ventricular septum: the case against clinical significance of myocardial bridging or coronary tunnel. Am Heart $\mathcal{F}$ 1982; 104:303-5.

7 Ciampricotti R, El Gamal M. Vasospastic coronary occlusion associated with a myocardial bridge. Cathet Cardiovasc Diagn 1988;14:118-20.

8 Rossi L, Dander B, Nidasio GP, Arbustini E. Paris B, Vassanelli C, et al. Myocardial bridges and ischemic heart disease. Eur Heart 7 1980;1:239-45.

9 Kramer JR, Kitazume H, Proudfit WL, Sones FM Jr. Clinical significance of isolated coronary bridges: benign and frequent condition involving the left anterior descending artery. Am Heart f 1982;103:282-8.

10 Angelini P, Trivellato M, Donis J, Leachman RD. Myocardial bridges: a review. Prog Cardiovasc Dis 1983;26:75-88.

11 Den Dulk D, Brugada P, Braat S, Heddle B, Wellens HJJ. Myocardial bridging as a cause of paroxysmal atrioventricular block. F Am Coll Cardiol 1983;1:965-70.

12 Feldman AM, BaughmanKL. Myocardial infarction associated with a myocardial bridge. Am Heart $\mathcal{F} 1986 ; 111: 784-$ 7 .

13 Vasan RS, Bahl VK, Rajano M. Myocardial infarction associated with a myocardial bridge. Int $\mathcal{F}$ Cardiol 1989;25:2401.

14 Bestetti RB, Costa RS, Zucolotto S, Oliviera JSM. Fatal outcome associated with autopsy proven myocardial bridging of the left anterior descending coronary artery. Eur Heart f 1989;10:573-6.

15 Morales AR, Romanelli R, Boucek RJ. The mural left anterior descending coronary artery, strenuous exercise and sudden death. Circulation 1980;62:230-7.

16 Lee SS, Wu TL. The role of the mural coronary artery in prevention of coronary atherosclerosis. Arch Pathol 1972; 93:32-5.

17 Ferreira AG Jr, Trotter SE, König B Jr, Decourt LV, Fox K, Olsen EGJ. Myocardial bridges: morphological and functional aspects. Br Heart 7 1991;66:364-7.

18 Ge J, Erbel R, Rupprecht HJ, Koch L, Kearney P, Gorge G, et al. Comparison of intravascular ultrasound and angiography in the assessment of myocardial bridging. Circulation 1994;89:1725-32.

19 Ge J, Erbel R, Görge G, Haude M, Meyer J. High wall shear stress proximal to myocardial bridging and atherosclerosis: intracoronary ultrasound and pressure measurements. $\mathrm{Br}$ Heart f 1995; 73:462-5.

20 Virmani R, Farb A, Burke AP. Ischemia from myocardial coronary bridging: fact or fancy? Hum Pathol 1993;24:6878.

21 Klues HG, Schwartz ER, Vom Dahl J, Reffelman R, Minartz $J$, Hanrath P. Intracoronary stent implantation-a new therapeutical approach in highly symptomatic patients with myocardial bridging [abstract]. F Am Coll Cardiol 1997;29: $220 \mathrm{~A}$. 